will introduce will be equivalent to a reduction in the size of the dish from 440 to $400 \mathrm{ft}$., but it will offer a new freedom in design. The dish inside will be free from the effect of the wind, and therefore will need to be designed to withstand only gravitational forces. It can be built of very light alloy, and the distortion of the structure in different positions can be taken up by hydraulic jacks. It should be possible to operate the telescope at wavelengths down to $5 \mathrm{~cm}$. The instrument will be mounted on a turntable, and carried on a horizontal beam with a row of bearings. The cost of the project-called Camroc-will be about $\$ 25$ million, and Dr Jerome Wiesner, Provost of MIT, has been elected chairman of the corporation which hopes to see it built.

In the West, there is another proposal for a large dish, this time $328 \mathrm{ft}$. in diameter. The project is supported by the University of Michigan, California Institute of Technology, Stanford University, and the University of California. Caltech has responsibility for the design, construction and ultimate operation of the instrument, which would be built at the Owen's Valley Observatory. The cost would be $\$ 17.8$ million, and again the NSF has been asked for support.

Meanwhile at the National Radio Astronomy Observatory at Greenbank there is a proposal to build a large array consisting of a series of smaller dishes. This project would be the most expensive, about $\$ 50$ million, but would cost a good deal less than an ambitious plan for a very large dish which was in the air at Greenbank some years ago.

\section{Fuss about Equipment}

THw fuss over equipment grants for British universities has broken out again. When the row first surfaced in May this year, bursars complained that the transition to a new system for equipment grants had left their science departments so short of money that students would have to be turned away. At the time, the University Grants Committee explained (Nature, 214,756 ; 1967) that the difficulty had been caused by the transition to the new system, and would soon resolve itself. Some university departments are now beginning to see much more discreditable motives behind the decisions. In a letter to The Times on July 17, Sir Cyril Hinshelwood and some of his colleagues from Imperial College claimed that the UGC had dishonoured firm pledges and gone back on financial commitments made in the past. Sir Cyril also saw a conscious decision to limit expenditure on equipment grants during 1967.

Ironically, there seems to be no doubt that the UGC has in fact provided more money for equipment this year than in 1966-67. The figures are $£ 22.5$ million for 1967-68, against $£ 21.5$ million in $1966-67$ and $£ 17$ million in 1965-66. In any normal year, this would have been enough, but this year is the last before the new quinquennium. Grants awarded at the beginning of the quinquennium for equipment have in many cases not been entirely taken up by the universities; in the past, the UGC has found that it often takes universities 6 or 7 years to draw the whole of the grant. On April 1, 1967, this unspent balance held by the UGC amounted to $£ 38$ million, to which universities felt they were entitled. To this extent, the $£ 22.5$ million which the UGC coaxed from the Treasury does represent a cut, of $£ 15.5$ million. The UGC says that this money will not be lost, but will go into the kitty when the new system starts to operate. The universities, on the other hand, may fear that if they do not get it out soon they will not get it at all.

The UGC claims to have foreseen the problem early in 1966 and to have discussed it with the ViceChancellors. The problem was again explained to the Vice-Chancellors in September 1966, and was the subject of a letter from Sir John Wolfenden to the universities in December 1966. In this letter, Sir John warned that it might be necessary to control the rate of drawings. In order to control the situation, the UGC decided to distribute the $£ 22.5$ million in two stages; $£ 20$ million in the first stage, leaving $£ 2.5$ million in reserve for universities which felt deprived. Universities were asked to make supplementary claims for this $£ 2.5$ million by June 31 ; when the claims came in, the UGC was alarmed to see that they amounted not to $£ 2.5$ million, but to $£ 21.5$ million. Clearly the reserve could not hope to keep the universities happy.

\section{Look, No Hands}

IN the engineering industry it is estimated that about 40 per cent of the production time consists of putting together finished components to produce the final article for sale. In the motor industry, the figure is even higher-60 per cent on assembly, and only 40 per cent on metal working. Faced with these figures, it is perhaps surprising that there has so far been no coherent attempt to automate the assembly process, cutting costs and releasing men for other jobs.

The Ministry of Technology is now trying to catch up with lost time. The minister, Mr Wedgwood Benn, announced on July 18 three projects for the development of automatic assembly. The first is a development contract with Staveley Industries to which the ministry will lend $£ 200,000$ over three years for the design and development of units which can be used as a basis for producing automatic assembly machines. Staveley will not be attempting to produce complete machines - the intention is to develop modular units which can be fitted together in different ways to do different jobs. A simple machine might be made up of a bowl feeder which selects one part from storage, an escapement mechanism which offers the part up in correct alignment with other parts, and a screw driving head which connects the two parts together. No human intervention will be necessary.

The ministry is also thinking of providing financial support for the Institution of Production Engineers, which is to produce what are called production data memoranda. These will supply engineers with the critical data needed to make use of automatic assembly, and will also include the availability of equipment and the economics of application. The ministry intends to support work in universities, starting with the Department of Production Engineering at the University of Nottingham. Professor Heginbotham and his team will be investigating the methods used for packaging parts, and teachable machines. These are machines which can be taught to carry out assembly functions by being first taken through the job by an operator and storing the information in a memory. 